\title{
A New version of Autonomous Ocean Energy Recovery System for Oceanic Applications
}

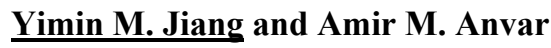 \\ School of Mechanical Engineering, \\ The University of Adelaide \\ Adelaide, South Australia, Australia \\ Emails:a1639948@student.adelaide.edu.au; amir.m.anvar@gmail.com
}

\begin{abstract}
Over 70\% of the earth's surface is covered by water and there is abundant energy in the sea. Imagine if people could make full use of the energy resources under the ocean, how profoundly it would change people's lives for the better. The energy that this research is concentrated on is from the surface wave motion, which is totally eco-friendly and to some extent 'endless'.

Ocean wave motion energy can be collected and transformed to useful energy by ocean wave energy conversion devices (OWECDs). Sea condition is complicated and wave force and motion are diverse in direction. However, most OWECs are designed to collect wave movement in a single-degree of freedom (DOF) and research has not considered various sea states.

In this research project, based on the study of the existing ocean energy recovery system research outcomes, a research-prototype of an autonomous multi-DOF OWEC device is presented, which is capable of collecting multi-DOF movement of ocean-waves independently. The concept and feasibility will be proved and the performance and efficiency under different sea states will be investigated. Different types of OWECs will be compared. The specific oceanic device (test-bed) has been optimized, simulated and manufactured.

In this research, the Finite Element Analysis (FEA) method was adopted. The process involved modelling the prototype using the CAD Inventor software, analyzing and simulating the interaction between ocean wave and the prototype using the ANSYS software and calculating the mechanical efficiency and output by using the software Abaqus.
\end{abstract}

Keywords: Wave energy, ocean, conversion devices, autonomous, energy recovery 


\section{INTRODUCTION}

In the present age, energy shortage has become one of the biggest global issues. Over $70 \%$ of the earth surface is covered by water and abundant energy is contained in the sea. Wave energy is one of the most common energies in the sea. Using the wave motion energy to produce power is totally eco-friendly and to some extent 'endless'. If the wave energy could be captured efficiently, it would not only solve the global energy shortage problem, but could also change the world for the better.

Ocean wave energy conversion devices (OWECDs) are commonly utilized to capture and transfer wave motion energy to useful power (for example, electricity). At present, various kinds of OWECDs have been invented, for example, Nodding Duck, Archimedes wave swing, SEAREV wave energy converter, Pelamis and WITT, to name just a few.

In this research study, a literature review is conducted to illustrate background information and current OWECD research status. The development of the ocean wave energy conversion systems and some famous OWECDs worldwide are investigated.

Currently, OWECDs researchers mainly concentrate on the single DOF motion transformation rather than multi DOF motion transformation. For instance, most of OWECDs are designed to collect merely vertical motion. However, wave motion is complicated and has multi-directional movement. So, it is underutilization of energy. For the purpose of durability and maintenance, constraining buoys into single DOF in oceanic environment requires extra effort as well. Consequently, a research on multi-motion conversion devices is needed. One of goals of this research project was to investigate, compare and analyse the differences between existing OWECDs and fill the gap.

Critical aspects of this project are:

- Insufficient models to simulate ocean waves.

- Test bed should be simple in structure and small in size for easy manufacturing and deploying.

- Analyze the shape of the buoy.

- Calculate the efficiency and internal force analysis.

- Consider different levels of sea states.

\section{THE NEW VERSION OF OCEAN ENERGY RECOVERY SYSTEM}

\subsection{Overview}

Ocean wave motion energy can be collected and transformed to useful energy by employing OWECDs. Sea conditions are complicated and wave force and motion are diverse in direction. However, most OWECDs are designed to collect wave movement in a single-DOF and research has not considered various sea states.

This investigation is based on the study of the existing ocean energy recovery system research outcomes, and a research-prototype of multi DOF OWEC device is presented, which is capable of collecting multi-DOF movement of ocean waves. The concept and feasibility is proved and the performance and efficiency under different sea states has been investigated. Furthermore, different types of OWECDs were compared. The specific oceanic device (test-bed) has been optimized, simulated and manufactured.

\subsection{Simplified Ocean Wave}

For the purpose of extracting power from ocean wave, parameters of ocean waves are required. The ocean wave is simplified into a linear model, as illustrated in Figure 1, with some characteristics demonstrated. 


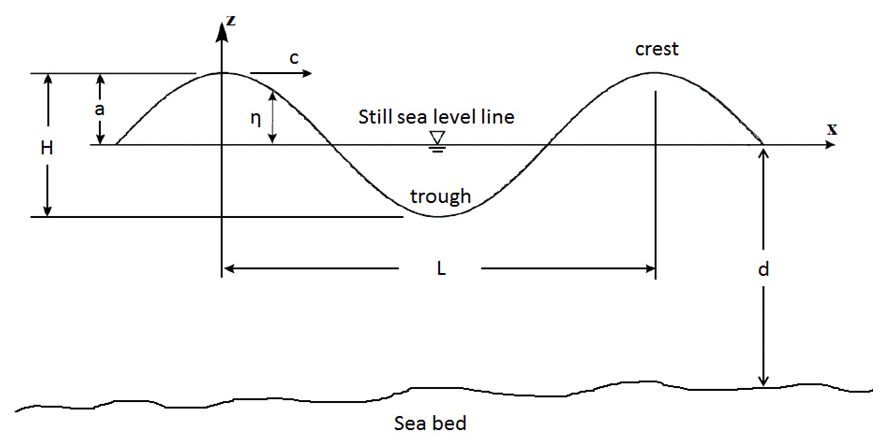

Figure 1. Simplified ocean wave.

We have obtained the displacement, horizontal direction, horizontal acceleration, vertical velocity and vertical acceleration of waves under sea states 1 to 8 (as illustrated in Table 1). It is noted that ocean wave length and wave period have been acquired by statistics analysis method. Displacement and velocity are calculated based on the collected data. However, in reality, ocean waves are complicated and unpredictable phenomena. The results from this analysis are for the ideal model of a one-dimensional simple wave.

Table 1. Velocity and acceleration under each sea state.

\begin{tabular}{|c|c|c|c|c|c|}
\hline $\begin{array}{c}\text { Sea } \\
\text { state } \\
\text { code }\end{array}$ & $\begin{array}{c}\text { Displacement } \\
(\mathrm{m})\end{array}$ & $\begin{array}{c}\text { velocity in the } \\
\text { horizontal } \\
\text { direction } \mathrm{u}(\mathrm{m} / \mathrm{s})\end{array}$ & $\begin{array}{c}\text { velocity in the } \\
\text { vertical direction } \\
\mathrm{W}(\mathrm{m} / \mathrm{s})\end{array}$ & $\begin{array}{c}\text { acceleration in } \\
\text { the horizontal } \\
\text { direction } \mathrm{a}_{\mathrm{x}} \\
\left(\mathrm{m} / \mathrm{s}^{2}\right)\end{array}$ & $\begin{array}{c}\text { acceleration in } \\
\text { the vertical } \\
\text { direction } \mathrm{a}_{\mathrm{z}}\left(\mathrm{m} / \mathrm{s}^{2}\right)\end{array}$ \\
\hline 0 & 0.00 & 0.00 & 0.00 & 0.00 & 0.00 \\
\hline 1 & $0.30 \cos (0.07 \mathrm{x}-0.84 \mathrm{t})$ & $0.25 \cos (0.07 \mathrm{x}-0.84 \mathrm{t})$ & $0.25 \sin (0.07 \mathrm{x}-0.84 \mathrm{t})$ & $0.21 \sin (0.07 \mathrm{x}-0.84 \mathrm{t})$ & $-0.21 \cos (0.07 \mathrm{x}-0.84 \mathrm{t})$ \\
\hline 2 & $1.50 \cos (0.07 \mathrm{x}-0.84 \mathrm{t})$ & $1.26 \cos (0.07 \mathrm{x}-0.84 \mathrm{t})$ & $1.26 \sin (0.07 \mathrm{x}-0.84 \mathrm{t})$ & $1.05 \sin (0.07 \mathrm{x}-0.84 \mathrm{t})$ & $-1.05 \cos (0.07 \mathrm{x}-0.84 \mathrm{t})$ \\
\hline 3 & $3.75 \cos (0.07 \mathrm{x}-0.84 \mathrm{t})$ & $3.14 \cos (0.07 \mathrm{x}-0.84 \mathrm{t})$ & $3.14 \sin (0.07 \mathrm{x}-0.84 \mathrm{t})$ & $2.63 \sin (0.07 \mathrm{x}-0.84 \mathrm{t})$ & $-2.63 \cos (0.07 \mathrm{x}-0.84 \mathrm{t})$ \\
\hline 4 & $7.5 \cos (0.05 \mathrm{x}-0.71 \mathrm{t})$ & $5.35 \cos (0.05 \mathrm{x}-0.71 \mathrm{t})$ & $5.35 \sin (0.05 \mathrm{x}-0.71 \mathrm{t})$ & $3.82 \sin (0.05 \mathrm{x}-0.71 \mathrm{t})$ & $-3.82 \cos (0.05 \mathrm{x}-0.71 \mathrm{t})$ \\
\hline 5 & $12.0 \cos (0.04 \mathrm{x}-0.65 \mathrm{t})$ & $7.77 \cos (0.04 \mathrm{x}-0.65 \mathrm{t})$ & $7.77 \sin (0.04 \mathrm{x}-0.65 \mathrm{t})$ & $5.03 \sin (0.04 \mathrm{x}-0.65 \mathrm{t})$ & $-5.03 \cos (0.04 \mathrm{x}-0.65 \mathrm{t})$ \\
\hline 6 & $18.0 \cos (0.03 \mathrm{x}-0.51 \mathrm{t})$ & $9.12 \cos (0.03 \mathrm{x}-0.51 \mathrm{t})$ & $9.12 \sin (0.03 \mathrm{x}-0.51 \mathrm{t})$ & $4.62 \sin (0.03 \mathrm{x}-0.51 \mathrm{t})$ & $-4.62 \cos (0.03 \mathrm{x}-0.51 \mathrm{t})$ \\
\hline 7 & $27.0 \cos (0.02 \mathrm{x}-0.42 \mathrm{t})$ & $11.3 \cos (0.02 \mathrm{x}-0.42 \mathrm{t})$ & $11.3 \sin (0.02 \mathrm{x}-0.42 \mathrm{t})$ & $4.73 \sin (0.02 \mathrm{x}-0.42 \mathrm{t})$ & $-4.73 \cos (0.02 \mathrm{x}-0.42 \mathrm{t})$ \\
\hline 8 & $42.0 \cos (0.01 \mathrm{x}-0.38 \mathrm{t})$ & $16.08 \cos (0.01 \mathrm{x}-0.38 \mathrm{t})$ & $16.08 \sin (0.01 \mathrm{x}-0.38 \mathrm{t})$ & $6.16 \sin (0.01 \mathrm{x}-0.38 \mathrm{t})$ & $-6.16 \cos (0.01 \mathrm{x}-0.38 \mathrm{t})$ \\
\hline
\end{tabular}

\subsection{Energy for Simplified Wave}

The energy of the one-dimensional simplified wave consists of the kinetic energy and potential energy of all water particles.

The potential energy for every unit cross section of the simplified wave is:

$$
\epsilon_{p}=\int_{0}^{\xi} \rho g z d z=\frac{1}{2} \rho g \xi^{2}
$$

The potential energy for unit width in one simplified wavelength is:

$$
E_{\mathrm{p}}=\int_{0}^{\lambda} \theta_{\mathrm{p}} d x=\frac{1}{2} \int_{0}^{\lambda} \rho g \xi^{2} d x=\frac{1}{16} \rho g H^{2} \lambda
$$

Meanwhile, in one simplified wavelength the kinetic energy is:

$$
E_{k}=\lambda \int_{-\infty}^{0} \frac{1}{2} \rho\left(u^{2}+\omega^{2}\right) d z=\frac{1}{16} \rho g H^{2} \lambda
$$

Thus, in a single wavelength, the amount of potential energy is equal to the amount of kinetic energy, which is $E$.

$$
\mathrm{E}^{\prime}=E_{\mathrm{p}} \mid E_{k}={ }_{j}^{1} g E^{2} \lambda
$$

This has shown that the power contained in a simple wave in one period is proportional to the wave height squared. For this reason, the wave power can be varied under different sea states. Usually, the fluctuation in deep sea has limited wave energy. Thus wave energy is mainly contained on the water surface.

The power of a simple wave has been deduced: 


$$
\mathrm{P}=H^{2} \mathrm{~T}
$$

\subsection{The Initial OWEC System Structure}

Generally, the structure of an OWEC system consists of a wave capturing device, wave conversion equipment and energy storage equipment. As illustrated in Figure 2, a research prototype is designed in this project. The wave capturing device is the cylinder buoy while the energy storage part is the generator.

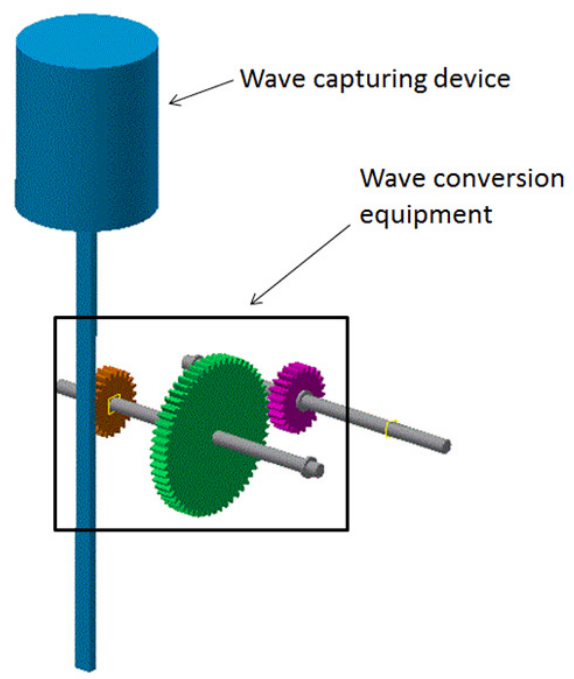

Figure 2. The construction of initial OWEC system structure.

When the buoy floats on the ocean surface, it moves up and down by ocean wave forces which have kinetic and potential energy. The rack that is connected to the buoy then has the up and down motion that drives the spur gear, which transforms the wave motion to circular motion. The motion is stored in the flywheel and drives the generator. This prototype is able to collect vertical wave motion, however, the mechanical loss tends to be considerable because of the orbit. Moreover, the rack is directly in contact with water when operating, which accelerates the corrosion of the part.

\section{NEW DESIGN OF OWEC PROTOTYPE}

\subsection{Structure and Operation}

In order to capture all directions of wave motion, the wave conversion equipment has been installed inside of the wave capturing equipment (buoy) which is shown in Figures 3 and 4 . As the buoy floats on the water, the impact of the wave makes it move in six DOF. The conversion device acquires the same movement as the buoy does. The kinetic energy and potential energy are activated in the pendulum and drive the bevel gear automatically. Eventually the wave movement is converted to kinetic energy of the flywheel and drives the generator autonomously.

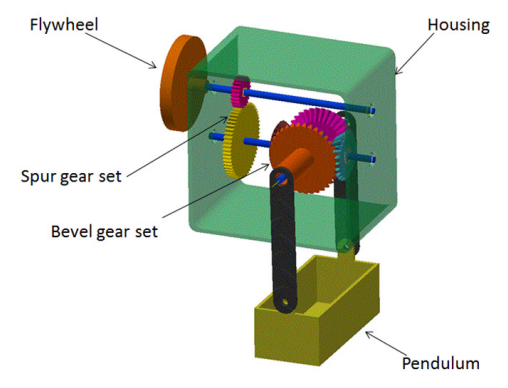

Figure 3. The optimized wave conversion equipment. 


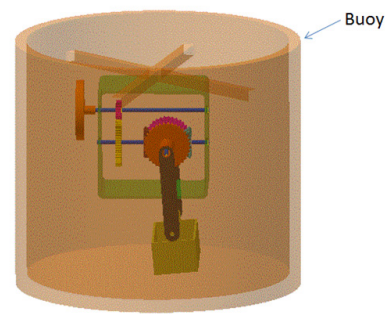

Figure 4. Assembled wave conversion equipment inside the buoy.

The pendulum in the wave conversion equipment is able to control the pitch and roll while operating. Each movement or combination of these two movements of the pendulum result in the spinning of the pendulum.

Inside each of the small bevel gears, there is a one-way clutch, which ensures the shafts spin in one direction continuously.

\section{SIMULATION}

\subsection{Setting up the Model in Abaqus Software}

The mesh of every part of the structure has been generated in hexahedral units, of type C3D8. There are 30120 meshes and 45832 nodes in the model.

Tie, hinge connector and contact were three types of constraining sets in this model. Spur gears were tied with shafts. The constraints between shafts and bearings were set as hinge connectors with the friction coefficient of 0.02 . It is noteworthy that one-way clutches were set as a hinge connector as well. In order to define a nonlinear damping with infinite damping in one spinning direction and no damping in the, gear engagements were set as "contact", with friction coefficient of 0.2 . The fully constrained model is shown in Figure 5.

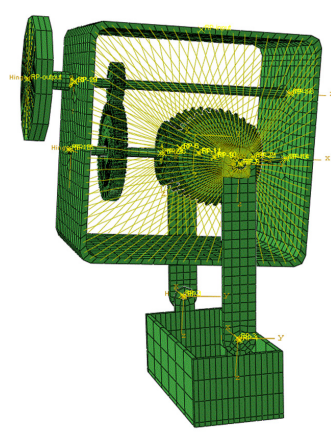

Figure 5. Fully constrained model.

\subsection{Efficiency of Wave Energy Conversion}

The efficiency for the wave energy conversion can be deduced by the output power of the flywheel divided by the input power of ocean wave.

$\eta=\frac{p_{\text {flywhel out }}}{P_{\text {ogen wase tiput: }}}$

In this case, the input power of a simplified ocean wave was obtained, thus only the average flywheel output power is needed.

For sea state 1, from Table 1, the input acceleration is:

$$
\mathrm{a}=-0.21 \cos (0.07 \mathrm{x}-0.84 \mathrm{t}), \mathrm{T}=7.2 \mathrm{~s}
$$


Jiang and Anvar, A New version of Ocean Energy Recovery System for Oceanic Applications

Some of the calculation results from Abaqus are listed in Table 2.

Table 2. Part of calculated data for sea state 1.

\begin{tabular}{|l|l|l|l|l|l|l|}
\hline $\begin{array}{l}\text { Time } \\
(\mathrm{sec})\end{array}$ & $\begin{array}{l}\text { Acceleration } \\
\text { input(m/s2) }\end{array}$ & $\begin{array}{l}\text { Output } \\
\text { angular } \\
\text { speed } \\
(\mathrm{rad} / \mathrm{sec})\end{array}$ & $\begin{array}{l}\text { Instantaneous } \\
\text { output power }\end{array}$ & $\begin{array}{l}\text { Increment } \\
(\mathrm{MW})\end{array}$ & $\begin{array}{l}\text { Accumulative } \\
\text { output energy } \\
(\mathrm{m} / \mathrm{s} 2)\end{array}$ & $\begin{array}{l}\text { Average } \\
\text { output } \\
\text { power } \\
(\mathrm{MW})\end{array}$ \\
\hline 0.36002 & 203769.3 & 29.20634 & 5951355 & 3607.715 & 279084.9 & 775192.8 \\
\hline 0.360623 & 204734.7 & 28.90255 & 5917354 & 3579.597 & 282664.5 & 783822.7 \\
\hline 0.361226 & 205701.1 & 28.72636 & 5909046 & 3566.836 & 286231.3 & 792388.4 \\
\hline 0.362131 & 206951.4 & 29.42198 & 6088921 & 5427.693 & 291659 & 805396.4 \\
\hline 0.36247 & 207880.9 & 29.71567 & 6177319 & 2080.964 & 293740 & 810384.3 \\
\hline 0.362979 & 208587.5 & 29.42373 & 6137420 & 3133.88 & 296873.9 & 817881.8 \\
\hline 0.363743 & 209653.3 & 29.19421 & 6120664 & 4679.01 & 301552.9 & 829027.4 \\
\hline 0.364506 & 210896.9 & 29.53543 & 6228932 & 4713.757 & 306266.6 & 840223.8 \\
\hline 0.36527 & 212144 & 29.86924 & 6336580 & 4796.358 & 311063 & 851597.4 \\
\hline 0.366033 & 213398.5 & 30.44223 & 6496327 & 4898.425 & 315961.4 & 863204.7 \\
\hline 0.366796 & 214661 & 30.62339 & 6573647 & 4988.916 & 320950.3 & 875010.4 \\
\hline 0.366987 & 215378.8 & 30.22797 & 6510463 & 1248.578 & 322198.9 & 877957.3 \\
\hline 0.367035 & 215553.9 & 29.92865 & 6451238 & 309.2242 & 322508.1 & 878684.9 \\
\hline 0.367107 & 215638 & 29.79428 & 6424777 & 460.8659 & 322969 & 879768 \\
\hline 0.367133 & 215713.1 & 29.66633 & 6399415 & 171.9858 & 323141 & 880174.2 \\
\hline 0.367174 & 215781.9 & 29.50715 & 6367110 & 257.0089 & 323398 & 880775.9 \\
\hline 0.367234 & 215865.8 & 29.24586 & 6313181 & 382.8148 & 323780.8 & 881674.4 \\
\hline
\end{tabular}

The average output power can be obtained by dividing the average value of the accumulative output energy by time.

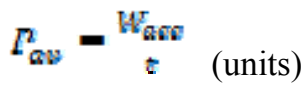

Thus, the efficiency under the sea state 1 is: ${ }^{*} 7_{1}=8.6 \%$

Similarly, the wave energy conversion efficiency under sea state 2,3 and 4 are $12.4 \%, 6.35 \%$ and $3.54 \%$, respectively.

The OWEC device has maximum efficiency under sea state 2 which is around $12.4 \%$. Compared to the previous OWEC device which has a wave energy conversion efficiency of $8 \%$, this optimized version of the OWEC device is more efficient in ocean wave collection.

\section{DISCUSSION AND CONCLUSIONS}

In this paper, the ocean wave parameters and a previous model of an automatic OWEC device have been analyzed and discussed. The new version of OWEC prototype has been modelled in Inventor software and simulated in Abaqus Software based on different sea states. The automatic ocean wave energy conversion efficiency has been considered under sea states $1,2,3$ and 4 . In the future, the following points are areas that can be investigated:

- The manufacturing of the research prototype and ocean trials. 
- An investigation into the efficiency improvement of the OWEC prototype.

- The mechanism improvement of the prototype.

- Optimization of the simulation method and process.

\section{ACKNOWLEDGMENTS}

The authors would like to express their gratitude to Mr John Van Velzen who has supported the processing of the project.

The authors acknowledge the efforts of The Australian government Department of Defence, Defence Science and Technology Group (DSTG) for the support, consulting and manufacturing towards the research model and for providing considerable time to this work.

\section{REFERENCES}

Bryden, IG \& Couch, SJ 2006, 'ME1 - marine energy extraction: tidal resource analysis, Renewable Energy, vol. 31 , no. 2, pp. 133-139.

California Energy Commission 2015, Ocean energy, viewed 14 March 2014, http://www.energy.ca.gov/releases/

Falnes J, Budal K. Wave-power conversion by power absorbers. International Journal of Ambient Energy, 1978, 6(1):2-11.

Kester Gunn*, Clym Stock-Williams. E.ON New Build \& Technology, K. Gunn, C. Stock-Williams / Renewable Energy 44 (2012) 296e304. 297

Leijon, M, Bernhoff, H, Berg, M \& Ågren, O 2003, 'Economical considerations of renewable electric energy production - especially development of wave energy', Renewable Energy, vol. 28, no. 8, pp. 1201-1209.

Naiko S, Nakamura S. Wave energy absorption in irregular waves by feed forward control system. In: Evans DV, Falcão A.F. de O, eds. Hydrodynamics of ocean wave energy utilization. Berlin: Springer, 1986. 269280.

NASA 2010, Tidal energy, viewed http://climatekids.nasa.gov/tidal-energy/

ThingLink 2014, viewed 6 May 2014, ocean energy, https://www.thinglink.com/scene/602172519981514752

Prudell, J, Stoddard, M, Amon, E, Brekken, TK \& von Jouanne, A 2010, 'A permanent-magnet tubular linear generator for ocean wave energy conversion', Industry Applications, IEEE Transactions on, vol. 46, no. 6, pp. 2392-2400. 